\title{
The Efficacy and Safety of Sodium-Glucose Cotransporter-2 Inhibitors in Patients with Advanced-Stage Diabetic Kidney Disease Taking Renin-Angiotensin System Blockers
}

This article was published in the following Dove Press journal:

Diabetes, Metabolic Syndrome and Obesity: Targets and Therapy

\author{
Keiji Hirai $(\mathbb{D}$ \\ Junki Morino \\ Saori Minato \\ Shohei Kaneko \\ Katsunori Yanai \\ Yuko Mutsuyoshi \\ Hiroki Ishii $\mathbb{D}$ \\ Momoko Matsuyama \\ Taisuke Kitano \\ Mitsutoshi Shindo \\ Akinori Aomatsu \\ Haruhisa Miyazawa \\ Kiyonori Ito \\ Yuichiro Ueda \\ Susumu Ookawara \\ Yoshiyuki Morishita \\ Division of Nephrology, First \\ Department of Integrated Medicine, \\ Saitama Medical Center, Jichi Medical \\ University, Saitama, Japan
}

Correspondence: Keiji Hirai

Division of Nephrology, First Department of Integrated Medicine, Saitama Medical Center, Jichi Medical University, I-847

Amanuma-Cho, Omiya-Ku, Saitama City, Saitama 330-8503, Japan

Tel +8I-48-647-2III

Fax +8I-48-647-683I

Email keijihirai@kfy.biglobe.ne.jp
Introduction and Objectives: We investigated the efficacy and safety of sodium-glucose cotransporter-2 (SGLT-2) inhibitors as an add-on therapy in patients with advanced-stage diabetic kidney disease taking renin-angiotensin system (RAS) blockers.

Materials and Methods: Changes in glycated hemoglobin (HbA1c), urine protein-tocreatinine ratio (UACR), body weight, systolic blood pressure, and annual change in estimated glomerular filtration rate (eGFR) were retrospectively analyzed in 20 patients after 12 months of SGLT-2 inhibitor administration (mean eGFR: $22.8 \pm 9.7 \mathrm{~mL} / \mathrm{min} /$ $1.73 \mathrm{~m}^{2}$ ). All patients had advanced-stage diabetic kidney disease and were taking RAS blockers. Twenty patients matched with similar propensity scores who were not taking SGLT-2 inhibitors served as the control group.

Results: The annual change in eGFR improved significantly from $-8.6 \pm 12.5 \mathrm{~mL} / \mathrm{min} /$ $1.73 \mathrm{~m}^{2} /$ year to $-2.6 \pm 5.0 \mathrm{~mL} / \mathrm{min} / 1.73 \mathrm{~m}^{2} /$ year after 12 months by SGLT-2 inhibitor administration $(p<0.05)$, but did not change in the control group. Other clinical parameters, such as HbA1c, UACR, body weight, blood pressure, serum lipids, and electrolytes did not change in either group. No adverse effects were observed by taking SGLT-2 inhibitors.

Conclusion: Using SGLT-2 inhibitors as an add-on therapy may have beneficial effects on renal function in patients with advanced-stage diabetic kidney disease taking RAS blockers without any adverse effects.

Keywords: advanced-stage diabetic kidney disease, renin-angiotensin system blocker, sodium-glucose cotransporter-2 inhibitor

\section{Introduction}

Diabetic kidney disease is a major complication of diabetes mellitus and is the leading cause of end-stage renal disease worldwide. ${ }^{1}$ Several studies have shown that renin-angiotensin system (RAS) blockers have renoprotective and blood pressure-lowering effects in patients with diabetic kidney disease, ${ }^{2,3}$ therefore, they are recommended as first-line antihypertensive agents for use in this population. ${ }^{4}$ Thus, many patients with diabetic kidney disease take RAS blockers.

Recently, sodium-glucose cotransporter-2 (SGLT-2) inhibitors have been developed as oral hypoglycemic agents. ${ }^{5}$ SGLT-2 inhibitors promote glucose and sodium excretion in urine by inhibiting renal glucose reabsorption, leading to pleiotropic effects, including improved glycemic control, lower blood pressure, and lower body weight. ${ }^{6}$ 
Furthermore, SGLT-2 inhibitors have been reported to have renoprotective effects, such as a reduction in the rate of decline in renal function and a reduction of proteinuria in patients with early- and middle-stage diabetic kidney disease taking RAS blockers. ${ }^{7-9}$ In addition, the combined use of SGLT-2 inhibitors and RAS blockers has been reported to be associated with synergistic renoprotective effects, including reductions in hyperfiltration, proteinuria, glomerular injury, and renal fibrosis in an animal model of diabetic kidney disease. ${ }^{10}$ These findings suggest that the administration of SGLT-2 inhibitors with RAS blockers may be beneficial for patients with early- and middle-stage diabetic kidney disease. However, it has not been established whether this combination therapy has similar effects in patients with advanced-stage diabetic kidney disease. Therefore, we investigated the efficacy and safety of the use of SGLT- 2 inhibitors as an add-on therapy in advanced-stage diabetic kidney disease patients taking RAS blockers.

\section{Materials and Methods Ethical Approval}

This study was approved by the Institutional Review Board of Saitama Medical Center, Jichi Medical University (S18114), Japan, and was conducted per the ethical principles contained in the Declaration of Helsinki. The requirement to obtain informed consent was waived because of the retrospective design. We displayed information regarding this study on our institutional notice board in waiting rooms and informed all patients of their right to opt-out.

\section{Patients}

We retrospectively analyzed the data of patients treated at Saitama Medical Center, Jichi Medical University, between 2015 and 2019. Inclusion criteria were: 1) patients aged $>20$ years; 2) diagnosed with type 2 diabetic kidney disease, with an estimated glomerular filtration rate (eGFR) $\leq 45 \mathrm{~mL} / \mathrm{min} /$ $1.73 \mathrm{~m}^{2} ; 3$ ) urine protein-to-creatinine ratio (UACR) $\geq 0.5 \mathrm{~g} / \mathrm{g}$ Cr; taking an SGLT-2 inhibitor for $\geq 12$ months; and 4) taking a RAS blocker for $\geq 12$ months before the initiation of the SGLT-2 inhibitor. Exclusion criteria were: 1) a diagnosis of type 1 diabetes mellitus or secondary diabetes mellitus; 2) malignancy; 3) severe infection; 4) steroid therapy; and 5) renal replacement therapy, such as hemodialysis, peritoneal dialysis, or renal transplantation. Patients without SGLT-2 inhibitor administration who met inclusion and exclusion criteria noted above except for SGLT-2 inhibitor administration were selected by propensity score matching for use as a control group.

\section{Study Design}

This study was a single-center, retrospective comparative study. A diagram of the study design is presented in Figure 1. Twenty patients were included in the SGLT-2

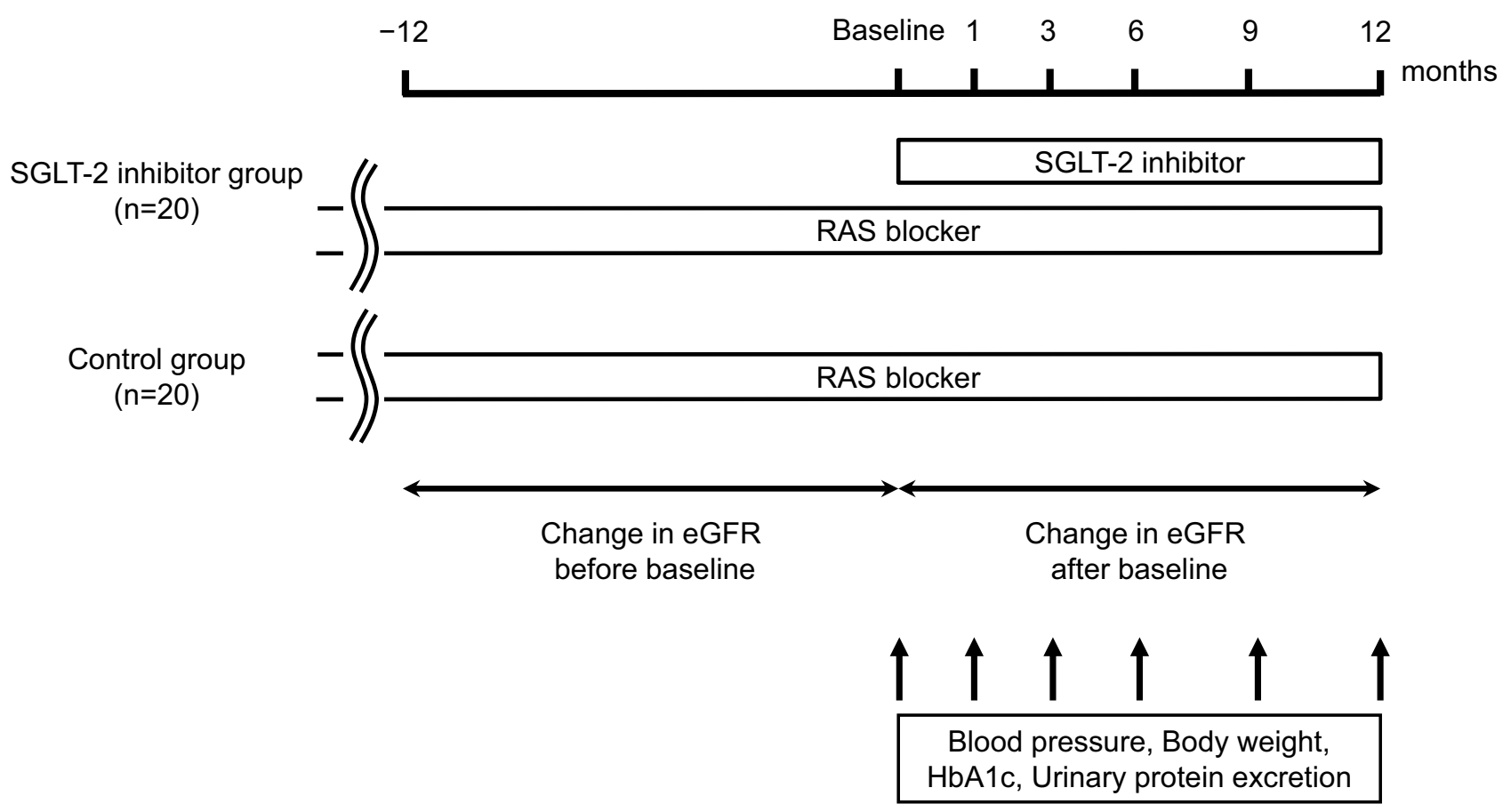

Figure I Study design diagram.

Abbreviations: eGFR, estimated glomerular filtration rate; HbAlc, glycated hemoglobin; RAS, renin-angiotensin system; SGLT-2, sodium-glucose cotransporter-2. 
inhibitor group and were compared with a control group of 20 patients matched for baseline characteristics. The baselines of each patient in the SGLT-2 inhibitor group were set up on the days on which an SGLT-2 inhibitor was initiated. In the control group, baselines were also set up during the study period. SGLT-2 inhibitors were administered orally once daily in the morning. Changes in the clinical data levels of glycosylated hemoglobin (HbA1c), UACR, body weight, and systolic blood pressure at 1, 3, 6, 9 , and 12 months were compared with those at baseline in each group. The annual changes in eGFR $(\mathrm{mL} / \mathrm{min} /$ $1.73 \mathrm{~m}^{2} /$ year) were evaluated 12 months before and after the baseline in each group.

\section{Laboratory Methods}

Blood and urinary parameters were determined by the Department of Clinical Laboratory, Saitama Medical Center. Serum HbA1c concentrations were presented as National Glycohemoglobin Standardization Program values. eGFR was calculated using a modified version of the Modification of Diet in Renal Disease formula of the Japanese Society of Nephrology as follows: eGFR (mL/ $\left.\min / 1.73 \mathrm{~m}^{2}\right)=194 \times$ age $^{-0.287} \times$ serum creatinine $^{-1.094}$ (multiplied by 0.739 for women). ${ }^{11}$ The annual change in eGFR was determined by linear regression analysis as the slope per month for each patient before and after baseline. Blood pressure was measured at rest in a sitting position using an automated arm cuff. Two measurements were taken, with a 1 - to 2 min interval between the measurements. The mean of these two measurements was used for the analyses.

\section{Statistics}

Statistical analysis was performed using JMP 11 (SAS Institute Inc., Cary, NC, USA). Propensity score matching analysis was used to select control patients with similar baseline characteristics. Independent variables that were included in the propensity model were: age,

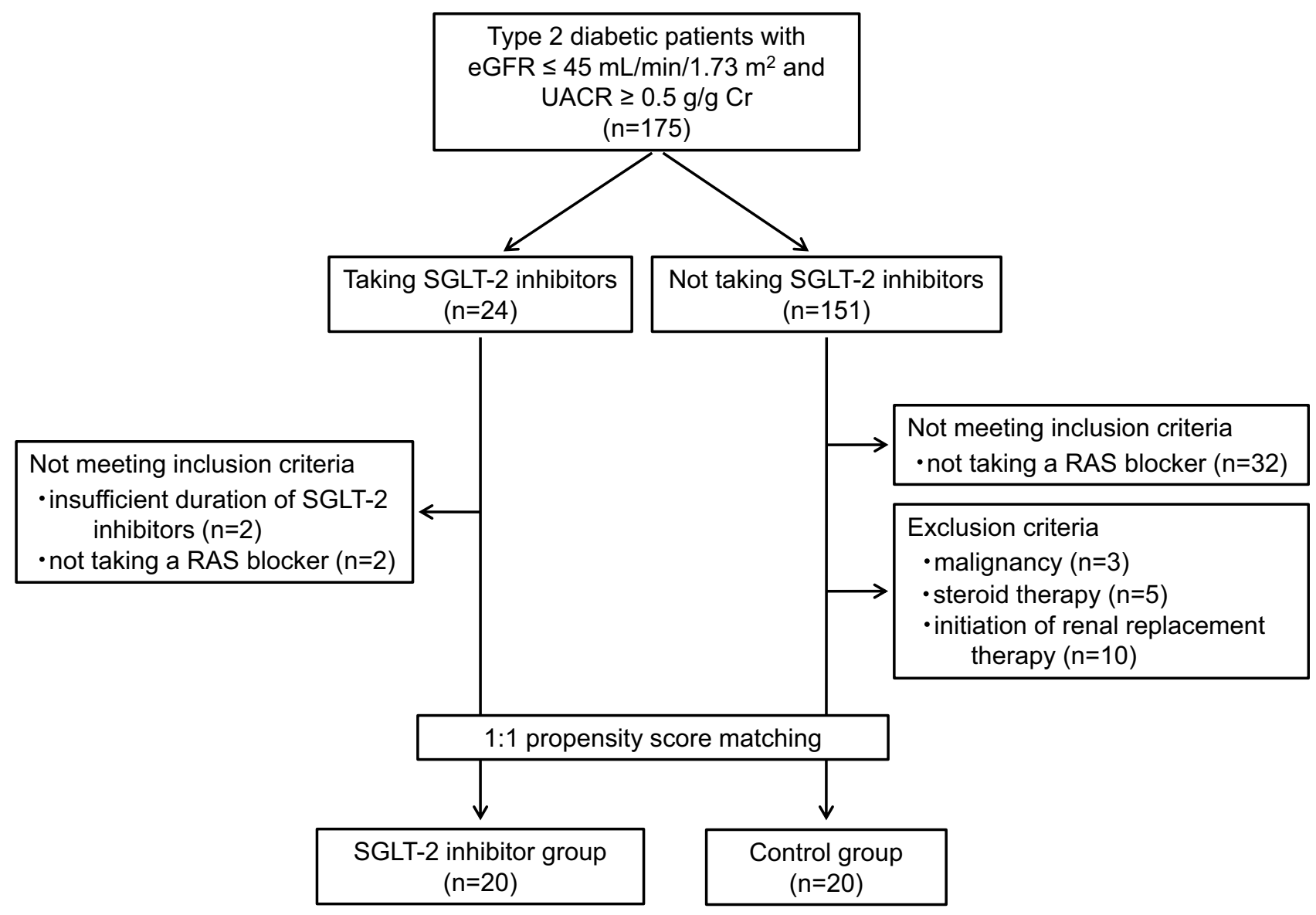

Figure 2 Patient flow diagram.

Abbreviations: eGFR, estimated glomerular filtration rate; RAS, renin-angiotensin system; SGLT-2, sodium-glucose cotransporter-2; UACR, urine protein-to-creatinine ratio. 
Table I Baseline Patient Characteristics

\begin{tabular}{|c|c|c|c|}
\hline & $\begin{array}{l}\text { SGLT-2 } \\
\text { Inhibitor } \\
\text { Group } \\
(n=20)\end{array}$ & $\begin{array}{l}\text { Control } \\
\text { Group } \\
(n=20)\end{array}$ & $p$-value \\
\hline Age (years) & $65.6 \pm 11.7$ & $67.1 \pm 16.0$ & 0.50 \\
\hline Sex (male/female) & $15 / 5$ & $17 / 3$ & 0.70 \\
\hline Body weight (kg) & $71.8 \pm 16.3$ & $75.9 \pm 22.5$ & 0.60 \\
\hline Body mass index $\left(\mathrm{kg} / \mathrm{m}^{2}\right)$ & $26.6 \pm 5.1$ & $28.6 \pm 8.5$ & 0.74 \\
\hline $\begin{array}{l}\text { Systolic blood pressure } \\
(\mathrm{mmHg})\end{array}$ & $138.2 \pm 14.2$ & $131.7 \pm 13.7$ & 0.21 \\
\hline $\begin{array}{l}\text { Diastolic blood pressure } \\
(\mathrm{mmHg})\end{array}$ & $72.3 \pm 11.0$ & $69.2 \pm 13.5$ & 0.24 \\
\hline Serum creatinine $(\mathrm{mg} / \mathrm{dL})$ & $2.5 \pm 0.8$ & $2.5 \pm 1.1$ & 0.88 \\
\hline eGFR $\left(\mathrm{mL} / \mathrm{min} / \mathrm{l} .73 \mathrm{~m}^{2}\right)$ & $22.8 \pm 9.7$ & $24.4 \pm 10.0$ & 0.49 \\
\hline CKD stage (number, \%) & & & \\
\hline G3b & $5(25.0 \%)$ & $6(30.0 \%)$ & 1.00 \\
\hline G4 & II (55.0\%) & II (55.0\%) & \\
\hline G5 & $4(20.0 \%)$ & $3(15.0 \%)$ & \\
\hline $\begin{array}{l}\text { Urinary protein excretion } \\
(\mathrm{g} / \mathrm{g} \mathrm{Cr})\end{array}$ & $3.2 \pm 3.1$ & $2.0 \pm 2.4$ & 0.06 \\
\hline HbAlc (\%) & $6.9 \pm 0.7$ & $7.0 \pm 0.9$ & 0.97 \\
\hline LDL-cholesterol (mg/dL) & $94.5 \pm 53.5$ & $79.8 \pm 19.8$ & 0.51 \\
\hline HDL-cholesterol (mg/dL) & $46.6 \pm 14.1$ & $43.7 \pm 8.8$ & 0.60 \\
\hline Triglyceride (mg/dL) & $210.0 \pm 171.4$ & $174.5 \pm 136.9$ & 0.88 \\
\hline Uric acid $(\mathrm{mg} / \mathrm{dL})$ & $6.1 \pm 1.4$ & $6.7 \pm 1.1$ & 0.05 \\
\hline Albumin $(g / d L)$ & $3.7 \pm 0.6$ & $4.0 \pm 0.5$ & 0.10 \\
\hline Hemoglobin $(g / d l)$ & $12.1 \pm 2.1$ & $11.8 \pm 1.7$ & 0.94 \\
\hline DPP-4 inhibitor (number, \%) & $9(45.0 \%)$ & $13(65.0 \%)$ & 0.34 \\
\hline $\begin{array}{l}\text { GLP-I receptor agonist } \\
\text { (number, \%) }\end{array}$ & $6(30.0 \%)$ & $4(20.0 \%)$ & 0.72 \\
\hline Sulfonylurea (number, \%) & $2(10.0 \%)$ & I (5.0\%) & 1.00 \\
\hline Glinide (number, \%) & $3(15.0 \%)$ & $4(20.0 \%)$ & 1.00 \\
\hline $\begin{array}{l}\alpha \text {-glucosidase inhibitor } \\
\text { (number, \%) }\end{array}$ & $2(10.0 \%)$ & $4(20.0 \%)$ & 0.66 \\
\hline Insulin (number, \%) & $9(45.0 \%)$ & $6(30.0 \%)$ & 0.51 \\
\hline RAS blocker (number, \%) & $20(100 \%)$ & $20(100 \%)$ & - \\
\hline $\begin{array}{l}\text { Angiotensin converting } \\
\text { enzyme inhibitor }\end{array}$ & $3(15.0 \%)$ & I (5.0\%) & 0.61 \\
\hline $\begin{array}{l}\text { Angiotensin II receptor } \\
\text { blocker }\end{array}$ & $17(85.0 \%)$ & $19(95.0 \%)$ & 0.61 \\
\hline Diuretics (number, \%) & $12(60.0 \%)$ & $12(60.0 \%)$ & 1.00 \\
\hline Loop diuretics & $12(60.0 \%)$ & $10(50.0 \%)$ & 0.75 \\
\hline Thiazide diuretics & $3(15.0 \%)$ & $5(25.0 \%)$ & 0.69 \\
\hline$\beta$-blocker (number, \%) & $5(25.0 \%)$ & $5(25.0 \%)$ & 1.00 \\
\hline $\begin{array}{l}\text { Calcium channel blocker } \\
\text { (number, \%) }\end{array}$ & $16(80.0 \%)$ & $16(80.0 \%)$ & 1.00 \\
\hline Statin (number, \%) & 14 (70.0\%) & $16(80.0 \%)$ & 0.72 \\
\hline $\begin{array}{l}\text { Eicosapentaenoic acid } \\
\text { (number, \%) }\end{array}$ & 7 (35.0\%) & $7(35.0 \%)$ & 1.00 \\
\hline
\end{tabular}

(Continued)
Table I (Continued).

\begin{tabular}{|l|l|l|l|}
\hline & $\begin{array}{l}\text { SGLT-2 } \\
\text { Inhibitor } \\
\text { Group } \\
(\mathbf{n = 2 0 )}\end{array}$ & $\begin{array}{l}\text { Control } \\
\text { Group } \\
(\mathbf{n = 2 0 )}\end{array}$ & p-value \\
\hline $\begin{array}{l}\text { Antiplatelet agent } \\
\text { (number, \%) } \\
\begin{array}{l}\text { Antihyperuricemic drug } \\
\text { (number, \%) }\end{array}\end{array}$ & $5(25.0 \%)$ & $7(35.0 \%)$ & 0.73 \\
\hline
\end{tabular}

Abbreviations: CKD, chronic kidney disease; DPP4, dipeptidyl peptidase-4; eGFR, estimated glomerular filtration rate; GLP-I, glucagon-like peptide-I; HbAlc, glycated hemoglobin; HDL, high-density lipoprotein; LDL, low-density lipoprotein; RAS, renin-angiotensin system; SGLT-2, sodium-glucose cotransporter-2.

Table 2 Dose of Each SGLT-2 Inhibitor Administered

\begin{tabular}{|l|l|l|}
\hline SGLT-2 Inhibitor & Dose (mg/day) & Number of Patients (\%) \\
\hline Empagliflozin & 10 & $\mathrm{I}(5 \%)$ \\
\hline Canagliflozin & 50 & $4(20 \%)$ \\
& 100 & $4(20 \%)$ \\
\hline Tofogliflozin & 10 & $9(45 \%)$ \\
& 20 & $2(10 \%)$ \\
\hline
\end{tabular}

Abbreviation: SGLT-2, sodium-glucose cotransporter-2.

sex, body mass index, blood pressure, HbA1c, eGFR, UACR, dipeptidyl peptidase-4 inhibitor use, and glucagon-like peptide-1 agonist use. One-to-one matching was performed by identifying a control patient with the nearest logit-transformed propensity score with a 0.25 caliper width, and the resulting score-matched pairs were used in subsequent analyses. Data are expressed as means \pm standard deviations. Comparisons of component ratios between the two groups were performed using Fisher's exact test. Comparisons of clinical parameters between the two groups were performed using the Mann-Whitney $U$-test. Comparisons of clinical parameters within each group at baseline, and at 1, 3, 6, 9, and 12 months from baseline, were performed using Friedman test and SteelDwass test. Comparisons of the annual change in eGFR before and after baseline in each group were performed using paired $t$-tests. The annual changes in clinical parameters were determined by linear regression analysis, and calculated as the monthly slope for each patient. Correlations between two variables were examined by linear regression analysis. Differences with $p<0.05$ were considered to be statistically significant. 


\section{Results}

\section{Patient Characteristics}

A total of 175 patients with type 2 diabetes and eGFR $\leq 45 \mathrm{~mL} /$ $\mathrm{min} / 1.73 \mathrm{~m}^{2}$ and UACR $\geq 0.5 \mathrm{~g} / \mathrm{g}$ Cr were identified. Twentyfour of these patients were taking SGLT-2 inhibitors, and 151 were not. Four of the patients taking SGLT-2 inhibitors did not meet inclusion criteria, resulting in the inclusion of 20 patients in the SGLT-2 inhibitor group. Twenty patients not undergoing treatment with SGLT-2 inhibitors who were individually matched to the patients in the SGLT-2 inhibitor group by propensity score were assigned to the control group (Figure 2). In total, forty patients were analyzed (32 men and 8 women, mean age $66.3 \pm 13.8$ years). Their mean eGFR levels at baseline was $23.6 \pm 9.8 \mathrm{~mL} / \mathrm{min} / 1.73 \mathrm{~m}^{2}$, and their chronic kidney disease stages were: stage G3b, 11 (27.5\%); stage G4, 22 (55.0\%); and stage G5, 7 (17.5\%). No patient was initiated with renal replacement therapy during the study period. Next, 20 patients were categorized into the SGLT- 2 inhibitor group, and 20 patients were categorized into the control group. Baseline characteristics of the patients and the medications in the two groups are summarized in Table 1. There were no significant differences in all clinical parameters between the two groups. The doses of each SGLT-2 inhibitor administered are summarized in Table 2 .

\section{Effects of SGLT-2 Inhibitors on Glycemic Control}

HbA1c levels in the SGLT-2 inhibitor group significantly decreased from $6.9 \pm 0.7$ at baseline to $6.5 \pm 0.6$ at 9 months $(p<0.05)$, but were not significantly different from baseline after 1, 3, 6, and 12 months. HbA1c levels in the control group at 1,3,6, 9, and 12 months did not change compared with the baseline (Figure 3).

\section{Effects of SGLT-2 Inhibitors on UACR and the Annual Change in eGFR}

UACR at 1,3, 6, 9, and 12 months did not change compared with baseline in either the SGLT-2 inhibitor or control groups (Figure 4). The annual change in eGFR improved significantly from $-8.6 \pm 12.5 \mathrm{~mL} / \mathrm{min} / 1.73 \mathrm{~m}^{2} /$ year before baseline to $-2.6 \pm$ $5.0 \mathrm{~mL} / \mathrm{min} / 1.73 \mathrm{~m}^{2} /$ year over the 12 months following the baseline measurements in the SGLT-2 inhibitor group $(p<$

\section{Changes in $\mathrm{HbA} 1 \mathrm{c}$}

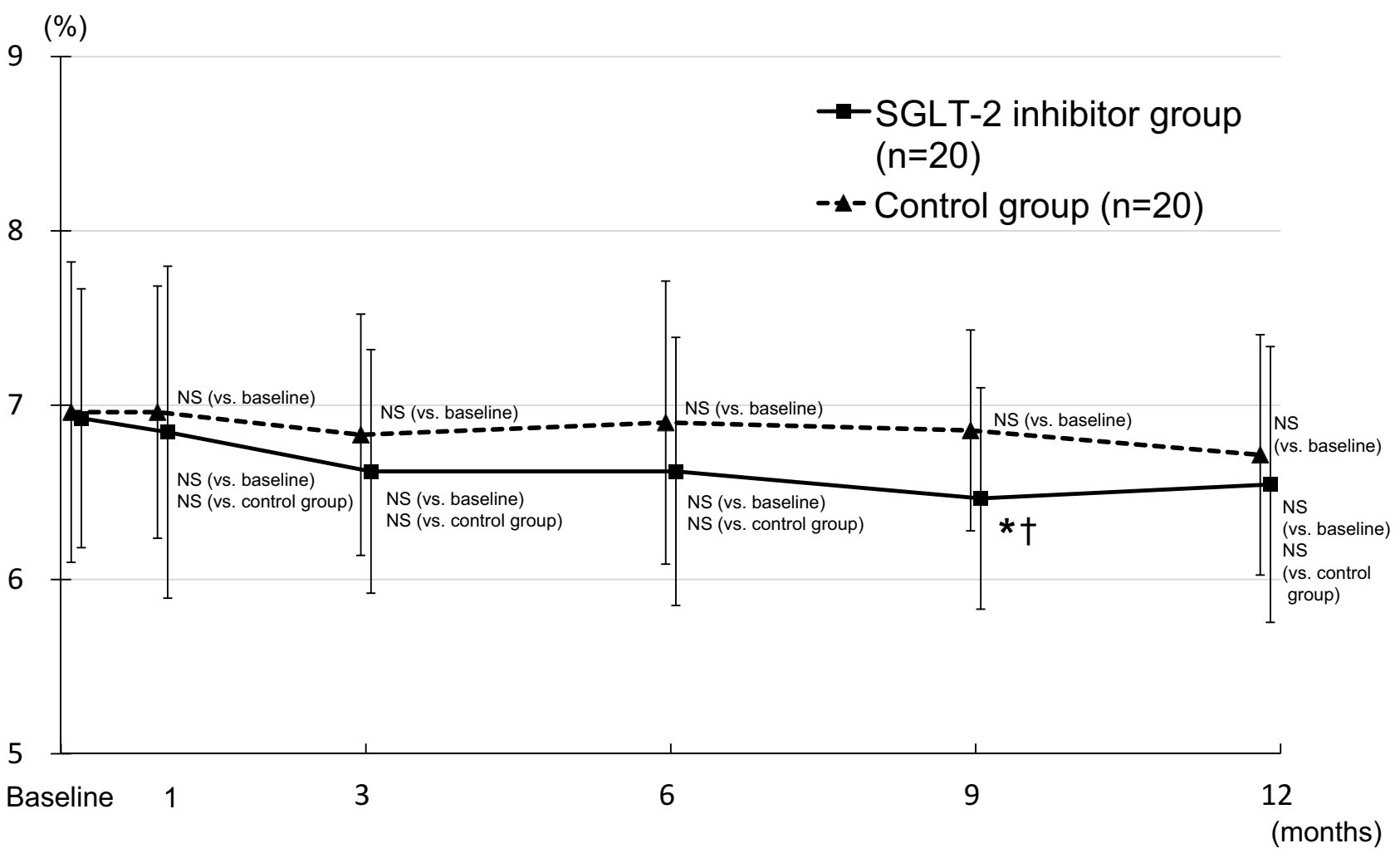

Figure 3 Changes in HbAlc in the SGLT-2 inhibitor and control groups. ${ }^{*} p<0.05$ vs. baseline; ${ }^{\dagger} p<0.05$ vs. the control group.

Abbreviations: HbAlc, glycated hemoglobin; NS, not significant; SGLT-2, sodium-glucose cotransporter-2. 


\section{Changes in UACR}

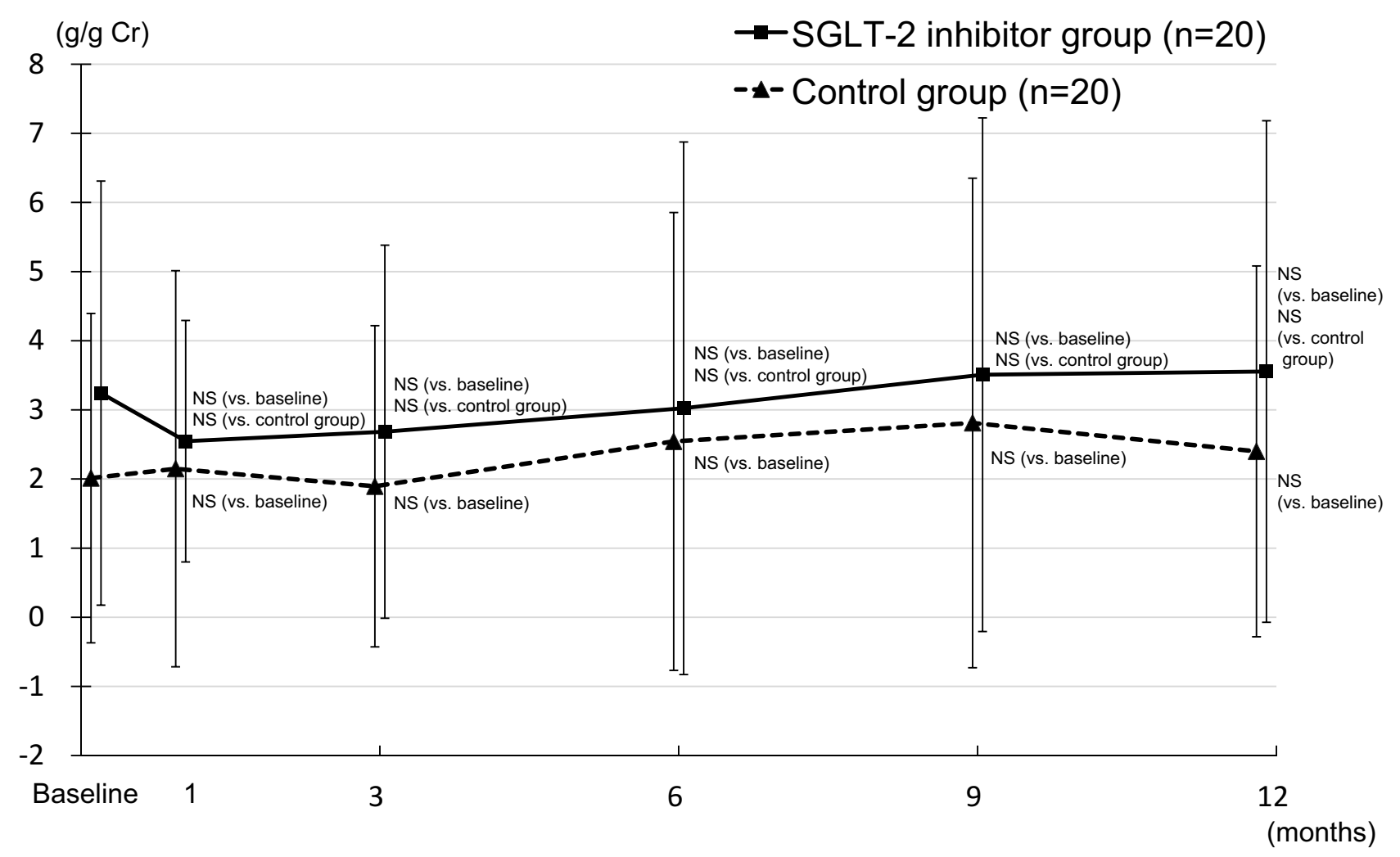

Figure 4 Changes in UACR in the SGLT-2 inhibitor and control groups.

Abbreviations: NS, not significant; SGLT-2, sodium-glucose cotransporter-2; UACR, urine protein-to-creatinine ratio.

0.05) (Figure 5 and 6). The annual change in eGFR did not differ between the before and after baseline levels in the control group [ $-5.7 \pm 6.5 \mathrm{~mL} / \mathrm{min} / 1.73 \mathrm{~m}^{2} /$ year (from -12 months to baseline) vs. $-4.9 \pm 5.4 \mathrm{~mL} / \mathrm{min} / 1.73 \mathrm{~m}^{2} /$ year (from baseline to +12 months), $p=0.57]$. We also performed simple linear regression analysis to examine the relationship between the annual change in eGFR from baseline to +12 months and the annual changes in age, body weight, systolic blood pressure, HbA1c, and UACR from baseline to +12 months in each group. However, there was no correlation between annual change in eGFR from baseline to +12 months and any of these parameters in either group (Supplemental Table 1). The decline in eGFR from baseline to +1 month was significantly greater in the SGLT-2 inhibitor group compared with the control group $(-2.5 \pm 4.0 \mathrm{~mL} / \mathrm{min} /$ $1.73 \mathrm{~m}^{2}$ vs $\left.-0.5 \pm 2.7 \mathrm{~mL} / \mathrm{min} / 1.73 \mathrm{~m}^{2}, p<0.05\right)$. In contrast, the decline in eGFR from +1 month to +12 months was significantly smaller in the SGLT-2 inhibitor group compared with the control group $\left(-0.9 \pm 5.6 \mathrm{~mL} / \mathrm{min} / 1.73 \mathrm{~m}^{2}\right.$ vs $-4.6 \pm 5.3 \mathrm{~mL} / \mathrm{min} /$ $\left.1.73 \mathrm{~m}^{2}, p<0.05\right)$.

\section{Changes in Other Clinical Parameters and Adverse Effects}

Other clinical and laboratory parameters, including body weight (Figure 7), systolic blood pressure (Figure 8), lowdensity lipoprotein cholesterol, high-density lipoprotein cholesterol, triglycerides, uric acid, albumin, hemoglobin, sodium, potassium, chloride, calcium, and phosphate were not significantly different from baseline after 1, 3, 6, 9, and 12 months in either the SGLT-2 inhibitor or control groups (data not shown). No adverse events, including hypoglycemia, severe hyperglycemia, diabetic ketoacidosis, genital or urinary tract infection, urosepsis, or acute kidney injury, were detected during the study period.

\section{Discussion}

In the present study, the use of SGLT-2 inhibitors as an add-on therapy to RAS blockers ameliorated the decline in renal function in patients with advanced-stage diabetic kidney disease (eGFR: $23.6 \pm 9.8 \mathrm{~mL} / \mathrm{min} / 1.73 \mathrm{~m}^{2}$ ) 


\section{Changes in eGFR}

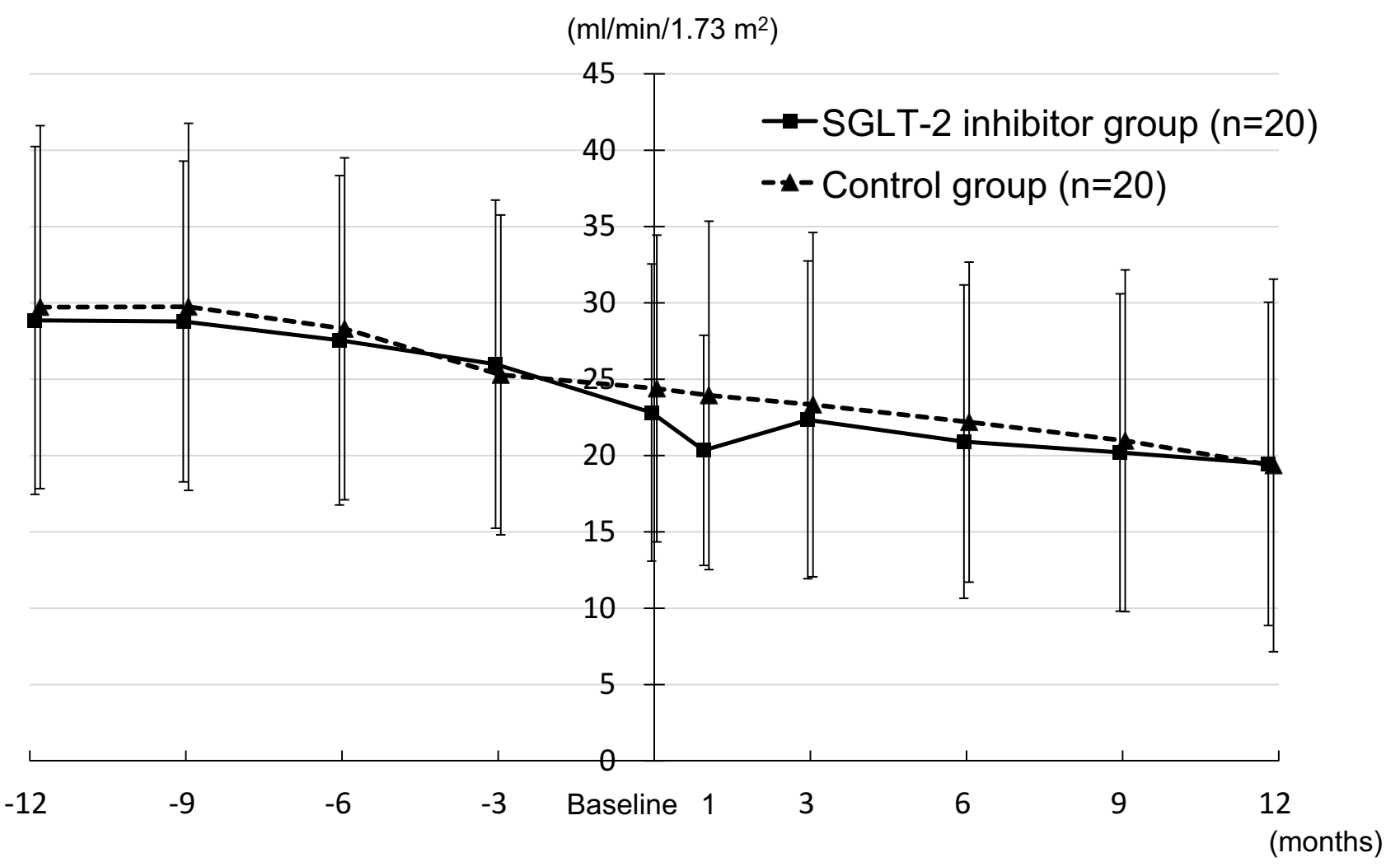

Figure 5 Changes in eGFR in the SGLT-2 inhibitor and control groups.

Abbreviations: eGFR, estimated glomerular filtration rate; SGLT-2, sodium-glucose cotransporter-2.

without any adverse events. These results suggest that the use of SGLT-2 inhibitors as an add-on therapy is safe, and has beneficial effects on renal function in patients with advanced-stage diabetic kidney disease.

Previous studies have shown that SGLT-2 inhibitors reduce proteinuria as well as reduce the rate of decline in renal function in patients with early- and mid-stage diabetic kidney disease. ${ }^{7-9}$ In the present study, the addition of an SGLT-2 inhibitor did not reduce proteinuria. However, the patients in our study had much more proteinuria than patients in the previous studies, ${ }^{7-9}$ which might explain this disparity. Another possibility is that SGLT-2 inhibitors may not have anti-proteinuric effects in patients with advanced-stage diabetic kidney disease who are taking RAS blockers. Additional clinical studies are needed to investigate the effects of SGLT-2 inhibitors on proteinuria in this population.

Because SGLT-2 inhibitors require sufficient glomerular filtration and reabsorption of glucose and sodium by the proximal tubule to lower blood glucose and reduce body fluid volume, ${ }^{5,12}$ their blood glucose-lowering effect and diuretic effect are thought to be impaired or eliminated in patients with poor renal function. ${ }^{13}$ In the present study, SGLT-2 inhibition did not reduce HbA1c concentration, body weight, or systolic blood pressure. These results suggest that SGLT-2 inhibitors may not have a beneficial effect on glycemic control and blood pressure control in advanced-stage diabetic kidney disease patients taking RAS blockers.

SGLT-2 inhibitors improve vasodilation of the afferent arteriole through activation of tubuloglomerular feedback by increasing the excretion of glucose in the urine. ${ }^{14}$ SGLT-2 inhibitors have also reported to improve tubulointerstitial hypoxia through suppression of oxygen consumption by inhibiting SGLT-2 in proximal tubules. ${ }^{15}$ Furthermore, SGLT-2 inhibitors prevent podocyte loss and reduce mesangial expansion via inhibition of macrophage 


\section{Annual changes in eGFR before and after baseline}

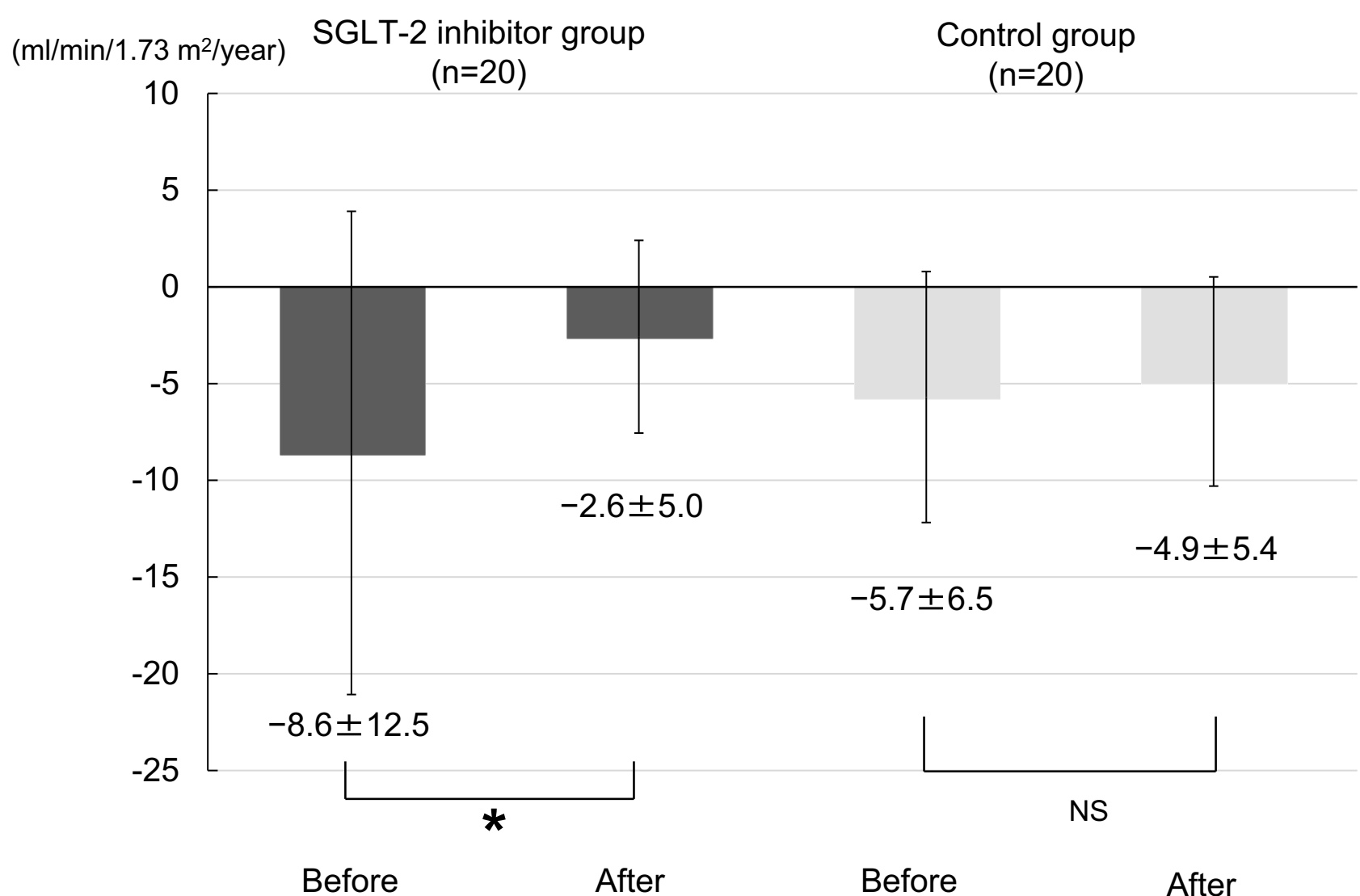

Figure 6 Annual change in eGFR before and after baseline in the SGLT-2 inhibitor and control groups. $*_{p}<0.05$.

Abbreviations: eGFR, estimated glomerular filtration rate; NS, not significant; SGLT-2, sodium-glucose cotransporter-2.

infiltration and proinflammatory cytokine expression. ${ }^{16}$ Thus, SGLT-2 inhibitors may prevent the worsening of renal function in patients with advanced-stage diabetic kidney disease through these mechanisms, independent of their blood glucose-lowering and diuretic effects. In our study, renal function 12 months before baseline and 12 months after baseline was similar between the two groups. However, the annual decline in renal function was ameliorated after initiation of SGLT-2 inhibitors. In addition, the decline in renal function from +1 month to +12 months was smaller in the SGLT-2 inhibitor group compared with the control group, which is consistent with the findings of previous studies. ${ }^{7-9}$ More than half of the patients in the present study were taking tofogliflozin, a potent and highly selective SGLT-2 inhibitor. ${ }^{17}$ Tofogliflozin has been reported to reduce proteinuria and renal tubular damage markers in patients with early-to-middle stage diabetic kidney disease. ${ }^{18}$ The use of tofogliflozin by a large proportion of the patients in the SGLT-2 inhibitor group could explain the renoprotective effect that we observed for SGLT-2 inhibitors. These results suggest that SGLT-2 inhibitors may have beneficial effects on renal function in patients with advanced-stage diabetic kidney disease who are taking RAS blockers. Further large-scale, long-term studies are needed to confirm the renoprotective effects of each SGLT-2 inhibitor in this population.

In the present study, the decline in renal function from baseline to +1 month was greater in the SGLT- 2 inhibitor group compared with in the control group. This initial drop in renal function after initiation of SGLT-2 inhibitors is thought to be due to reduced glomerular filtration pressure via constriction of the afferent arteriole, and has been noted in large-scale clinical trials involving patients with diabetic kidney disease taking RAS blockers. ${ }^{7-9}$ It has been reported that SGLT-2 inhibitors may increase the risk of acute kidney injury when 


\section{Changes in body weight}

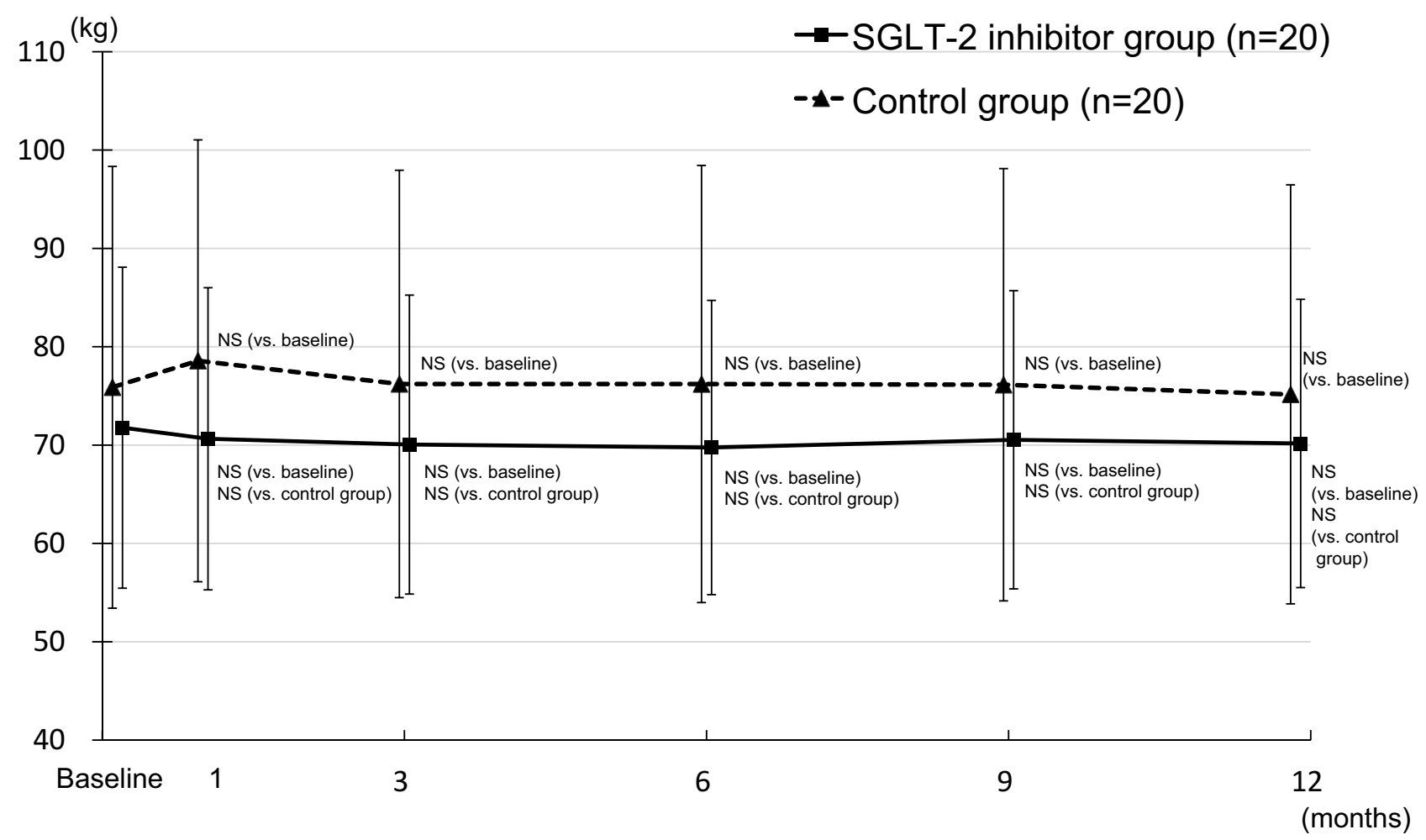

Figure 7 Changes in body weight in the SGLT-2 inhibitor and control groups. Abbreviations: NS, not significant; SGLT-2, sodium-glucose cotransporter-2.

used concomitantly with RAS blockers ${ }^{19}$ because RAS blockers also reduce glomerular filtration pressure via dilation of the efferent arteriole. However, in our study, no adverse events, including acute kidney injury, electrolyte disorders, or urinary tract infections, were observed. This suggests that SGLT-2 inhibitors may be used safely in patients with advanced-stage diabetic kidney disease who are taking RAS blockers. Further large-scale, long-term studies are needed to assess the safety of SGLT-2 inhibitors in this population.

This study had several limitations. First, it was a single-center retrospective observational study, and therefore, patient selection bias might have been present although propensity score matching was performed to reduce selection bias in the control group. Second, the number of participants in the study was small, and the study was performed at a single center, limiting the generalizability of the findings. Third, most patients were taking antihypertensive drugs other than RAS blockers and SGLT-2 inhibitors, such as diuretics, $\beta$-blockers, and calcium channel blockers. However, it seems unlikely that these drugs affected the study results, because there were no differences in baseline characteristics, including the use of antihypertensive drugs, between the two groups after propensity score matching, and the patients' use of antihypertensive drugs did not change during the study period. Therefore, large-scale, long-term, randomized clinical studies are required to confirm the efficacy of SGLT-2 inhibitors for renoprotection in patients with advanced-stage diabetic kidney disease. Ongoing large clinical trials including the EMPA-KIDNEY study and the DAPACKD trial ${ }^{20}$ could help clarify the efficacy and safety of SGLT-2 inhibitor use in patients with moderate-to-severe chronic kidney disease taking RAS blockers.

In conclusion, SGLT-2 inhibitors ameliorate the decline in renal function in patients with advanced-stage diabetic kidney disease who are taking RAS blockers. These findings suggest that the use of SGLT-2 inhibitors as an add-on therapy is safe and renoprotective in patients with advancedstage diabetic kidney disease taking RAS blockers. 


\section{Changes in systolic blood pressure}

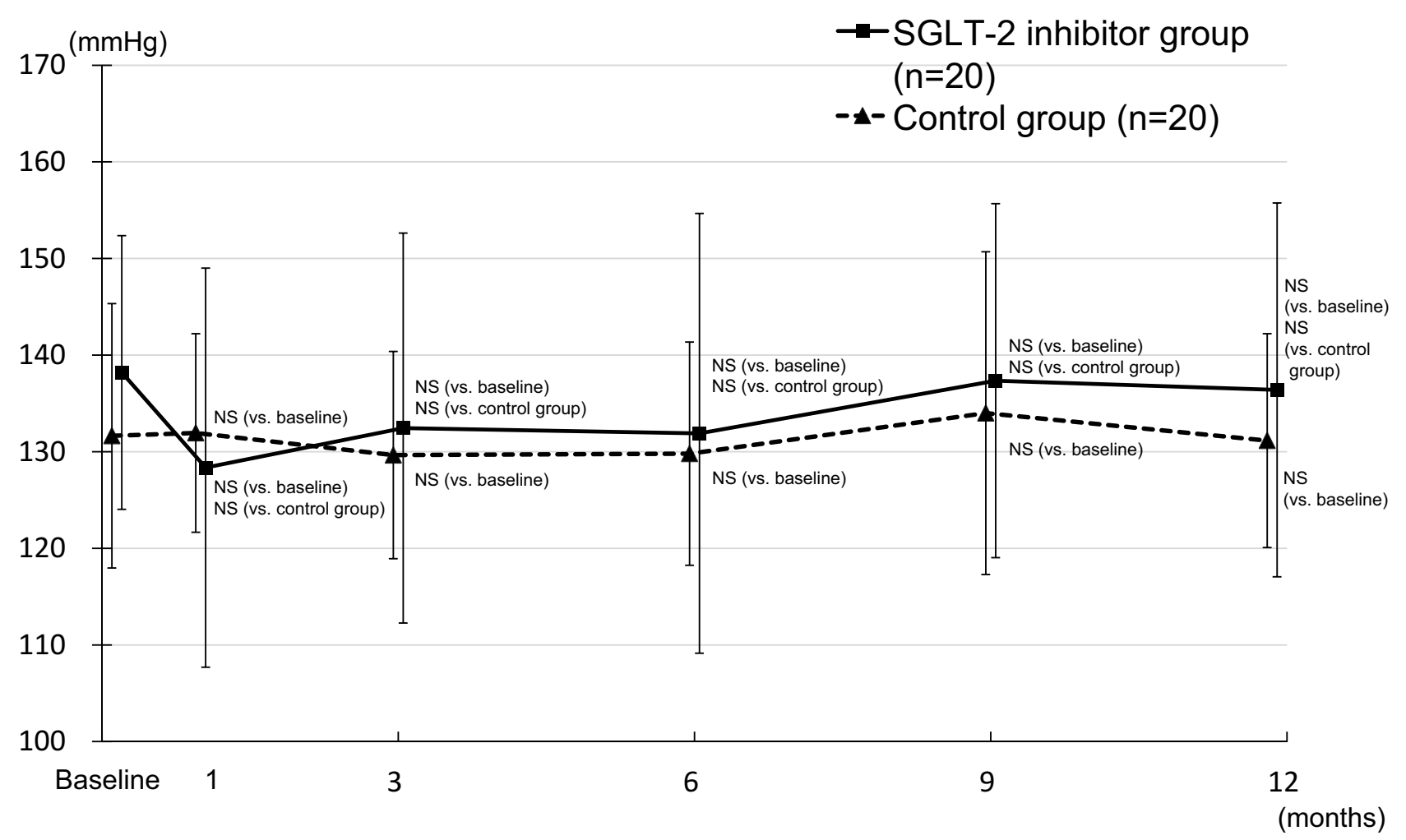

Figure 8 Changes in systolic blood pressure in the SGLT-2 inhibitor and control groups. Abbreviations: NS, not significant; SGLT-2, sodium-glucose cotransporter-2.

\section{Acknowledgments}

The authors thank all the medical staff of the institution for their excellent medical care support. We thank Katrina Krogh, MD, from Edanz Group for editing a draft of this manuscript.

\section{Disclosure}

The authors report no conflicts of interest in this work.

\section{References}

1. Ghaderian SB, Hayati F, Shayanpour S, Beladi Mousavi SS. Diabetes and end-stage renal disease; a review article on new concepts. $J$ Renal Inj Prev. 2015;4(2):28-33. doi:10.12861/jrip.2015.07

2. Strippoli GF, Craig M, Deeks JJ, Schena FP, Craig JC. Effects of angiotensin converting enzyme inhibitors and angiotensin II receptor antagonists on mortality and renal outcomes in diabetic nephropathy: systematic review. BMJ. 2004;329(7470):828. doi:10.1136/bmj.3823 7.585000.7C

3. Palmer SC, Mavridis D, Navarese E, et al. Comparative efficacy and safety of blood pressure-lowering agents in adults with diabetes and kidney disease: a network meta-analysis. Lancet. 2015;385(9982):20 47-2056. doi:10.1016/S0140-6736(14)62459-4

4. Group KDIGOKCW. KDIGO 2012 clinical practice guideline for the evaluation and management of chronic kidney disease. Kidney Int Suppl. 2013;3:1-150.
5. Abdul-Ghani MA, DeFronzo RA, Norton L. Novel hypothesis to explain why SGLT2 inhibitors inhibit only $30-50 \%$ of filtered glucose load in humans. Diabetes. 2013;62(10):3324-3328. doi:10.2337/db13-0604

6. Zaccardi F, Webb DR, Htike ZZ, Youssef D, Khunti K, Davies MJ. Efficacy and safety of sodium-glucose co-transporter-2 inhibitors in type 2 diabetes mellitus: systematic review and network meta-analysis. Diabetes Obes Metab. 2016;18(8):783-794. doi:10.1111/dom.2016.18. issue-8

7. Cherney DZI, Zinman B, Inzucchi SE, et al. Effects of empagliflozin on the urinary albumin-to-creatinine ratio in patients with type 2 diabetes and established cardiovascular disease: an exploratory analysis from the EMPA-REG OUTCOME randomised, placebo-controlled trial. Lancet Diabetes Endocrinol. 2017;5(8):610-621. doi:10.1016/S2213-8587(17) 30182-1

8. Perkovic V, de Zeeuw D, Mahaffey KW, et al. Canagliflozin and renal outcomes in type 2 diabetes: results from the CANVAS program randomised clinical trials. Lancet Diabetes Endocrinol. 2018;6 (9):691-704. doi:10.1016/S2213-8587(18)30141-4

9. Perkovic V, Jardine MJ, Neal B, et al. Canagliflozin and renal outcomes in type 2 diabetes and nephropathy. $N$ Engl J Med. 2019;380 (24):2295-2306. doi:10.1056/NEJMoa1811744

10. Kojima N, Williams JM, Slaughter TN, et al. Renoprotective effects of combined SGLT2 and ACE inhibitor therapy in diabetic D ahl S rats. Physiol Rep. 2015;3(7):e12436. doi:10.14814/phy2.12436

11. Matsuo S, Imai E, Horio M, et al. Revised equations for estimated GFR from serum creatinine in Japan. Am J Kidney Dis. 2009;53 (6):982-992. doi:10.1053/j.ajkd.2008.12.034

12. Kimura G. Diuretic action of sodium-glucose cotransporter 2 inhibitors and its importance in the management of heart failure. Circ J. 2016;80(11):2277-2281. doi:10.1253/circj.CJ-16-0780 
13. Cherney DZI, Cooper ME, Tikkanen I, et al. Pooled analysis of Phase III trials indicate contrasting influences of renal function on blood pressure, body weight, and $\mathrm{HbA1c}$ reductions with empagliflozin. Kidney Int. 2018;93(1):231-244.

14. Cherney DZ, Perkins BA, Soleymanlou N, et al. Renal hemodynamic effect of sodium-glucose cotransporter 2 inhibition in patients with type 1 diabetes mellitus. Circulation. 2014;129(5):587-597. doi:10. 1161/CIRCULATIONAHA.113.005081

15. O’Neill J, Fasching A, Pihl L, Patinha D, Franzen S, Palm F. Acute SGLT inhibition normalizes $\mathrm{O} 2$ tension in the renal cortex but causes hypoxia in the renal medulla in anaesthetized control and diabetic rats. Am J Physiol Renal Physiol. 2015;309(3):F227-F234. doi:10.11 52/ajprenal.00689.2014

16. Wang XX, Levi J, Luo Y, et al. SGLT2 protein expression is increased in human diabetic nephropathy: SGLT2 protein inhibition decreases renal lipid accumulation, inflammation, and the development of nephropathy in diabetic mice. J Biol Chem. 2017;292 (13):5335-5348. doi:10.1074/jbc.M117.779520
17. Kim GW, Chung SH. Clinical implication of SGLT2 inhibitors in type 2 diabetes. Arch Pharm Res. 2014;37(8):957-966. doi:10.1007/ s12272-014-0419-0

18. Nunoi K, Sato Y, Kaku K, Yoshida A, Suganami H. Effects of sodium-glucose cotransporter 2 inhibitor, tofogliflozin, on the indices of renal tubular function in patients with type 2 diabetes. Endocrinol Diabetes Metab. 2018;1(2):e00015. doi:10.1002/edm2.15

19. Szalat A, Perlman A, Muszkat M, Khamaisi M, Abassi Z, Heyman SN. Can SGLT2 inhibitors cause acute renal failure? Plausible role for altered glomerular hemodynamics and medullary hypoxia. Drug Saf. 2018;41(3):239-252. doi:10.1007/s40264-0170602-6

20. Herrington WG, Preiss D, Haynes R, et al. The potential for improving cardio-renal outcomes by sodium-glucose co-transporter-2 inhibition in people with chronic kidney disease: a rationale for the EMPA-KIDNEY study. Clin Kidney J. 2018;11(6):749-761. doi:10. 1093/ckj/sfy090

Diabetes, Metabolic Syndrome and Obesity: Targets and Therapy

Dovepress

\section{Publish your work in this journal}

Diabetes, Metabolic Syndrome and Obesity: Targets and Therapy is an international, peer-reviewed open-access journal committed to the rapid publication of the latest laboratory and clinical findings in the fields of diabetes, metabolic syndrome and obesity research. Original research, review, case reports, hypothesis formation, expert opinion and commentaries are all considered for publication. The manuscript management system is completely online and includes a very quick and fair peer-review system, which is all easy to use. Visit http://www.dovepress.com/testimonials.php to read real quotes from published authors.

Submit your manuscript here: https://www.dovepress.com/diabetes-metabolic-syndrome-and-obesity-targets-and-therapy-journal 